\title{
Estimation of jumping distance using run-up velocity for male long jumpers
}

\author{
Bayraktar I. ${ }^{1 \mathrm{ABCDE}}$, Çilli M. ${ }^{2 \mathrm{ABCD}}$ \\ ${ }^{1}$ The Ministry of Youth and Sport, General Directorate of Sport, Ankara, Turkey \\ ${ }^{2}$ Faculty of Sport Sciences, Department of Coaching Education, Sakarya University, Turkey
}

Authors' Contribution: A - Study design; B - Data collection; C - Statistical analysis; D - Manuscript Preparation; E - Funds Collection.

\begin{abstract}
Purpose: $\quad$ The purpose of this study is to investigate the relationship between run-up velocity and jumping distance, and create a jumping distance estimation model that trainers may use practically for athletes at broad performance level. In a long jump, about ninety percent of the jumping distance is the athlete's flying distance, and horizontal velocity, which has the highest effect on flying distance among biomechanical factors, is highly important in long jumps. Therefore, especially the velocity of the athlete in the last ten meters of run-up is considered to be the most important determinant of performance.

Material: $\quad$ The research data was composed of 328 valid trials on 73 Turkish male long jumpers who were 18.7 ( \pm 2.8$)$ years old. As a result of the correlation statistics obtained in this study, a linear regression model was formed between last-ten-meter running velocity and jumping distance, which was observed to have the highest correlation.

Results: $\quad$ It was observed that the velocity for run-up in the last ten meters explained $76 \%$ of jumping distance. Based on the estimating equation, it may be stated that $0.1 \mathrm{~m} / \mathrm{s}$ of increase in run-up velocity for male long jumpers will increase their jumping distance by $10.7 \mathrm{~cm}$.

Conclusions: It was observed that especially the velocity in the last 10 meters of run-up was one of the most significant predictors of performance, and the estimation model established using the value of run-up velocity, which had the strongest relationship, was able to make high-accuracy estimations for both low and high values.

Keywords: long, jump, velocity, estimation, model.
\end{abstract}

\section{Introduction}

In long jump, the purpose of the athlete is to gain velocity on a running track, and achieve a jump from the takeoff board to the furthest point in the sand possible. The distance between the part of the trace he leaves on the sand that is the closest to the takeoff board and the jumping line, is defined as the official jumping distance.

A long jump is technically divided into four stages: 1) Run-up, 2) Jumping, 3) Flight and 4) Landing. A study which investigated the ratios of the total distance performance in long jumping based on these stages, found these ratios as $5.4 \%$ for jumping (L1), $92.9 \%$ for flight (L2) and $8.0 \%$ for landing (L3) [1]. In other words, about $90 \%$ of total jumping distance is the distance of the athlete's flight. This is why horizontal velocity, which has the highest effect on flying distance among biomechanical factors, is highly important in long jumps [2]. Success in long jumping is mostly dependent on athletes' velocity. It is known that some high-level long jumpers, like Carl Lewis and Marion Jones, are also high-level sprinters [3]. Fastest ones are not the best long jumpers, but it may be stated that the best long jumpers are the fastest ones. This has been seen in the long jumping biomechanical analysis report of the 2009 IAAF World Athletics Championship. It was seen in both men and women that the athletes who came first had higher run-up velocities than others [4]. In a study Beamon's, Powel and Lewis's, who have the three best records in all times, kinematics data was

(c) Bayraktar I., Çilli M., 2018

doi:10.15561/18189172.2018.0302 investigated. It was shown that the common characteristic of these athletes was that they all had $11 \mathrm{~m} / \mathrm{s}$ of horizontal velocity [5]. Linthorne [2] also emphasized that male long jumpers need to have a horizontal velocity value of 10.6 $\mathrm{m} / \mathrm{s}$ to reach 8.00 meters of jumping distance.

Running velocity is expected to increase with a certain rhythm. Especially the velocity of the athlete in the last 10 meters are considered as the most important indicators of performance. On the other hand, there is a decrease in running velocity towards the end of the approach run. Studies have shown that the most significant loss is experienced in the last 5 meters near the board [6].

Number of studies reported that in long jumping, run-up velocity is the most important determinant of performance [1,7-10]. Bridgett and Linthorne [10] reported a strong relationship of 0.96 between horizontal velocity and jumping distance. Similarly, many studies emphasized the relationship between running velocity and jumping distance [1,7-9,11,12]. Schulek [13] artificially increased the run-up velocities of high-level athletes with the towing method. When velocity is increased artificially there was a high increase in jumping distance [13]. With another aspect, an increase of $0.1 \mathrm{~m} / \mathrm{s}$ in run-up velocity

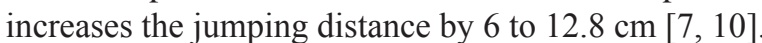

The studies of the relationship between running speed and performance revealed different correlation coefficients. The different correlation coefficients can be explained by some reasons. Such studies have generally been conducted with limited number of jumpers who have high-level technical skills and long jumping 
distances, and usually during a major competition. For example, Hay \& Miller [14] performed their study with 12 athletes in the long jump final of the 1984 Olympic Games in Los Angeles. Fukasiro [5] reported the data obtained during Mexico 1968, Seoul Olympic Games in 1988 and the 1991 Tokyo World Championship. Lees et al.'s study [8] focused on 12 athletes that ran at the 1991 World University Games to investigate the biomechanical component analyses selected for male athletes of long jumping. Nevertheless, it may be expected that studies on broader samples in terms of jumping distance and running velocity distribution in competitions may provide more useful results in investigating the relationship between run-up velocity and jumping distance, and making better estimations of jumping distance by usage of running velocity.

The purpose of this study is to investigate the relationships between run-up velocity variables of male long jumpers and jumping distance, and create a jumping distance estimation model that trainers may use practically.

\section{Material and methods}

Participants: The research data was composed of 328 valid trials of 73 Turkish male long jumpers who were $18.7( \pm 2.8)$ years old. The findings were obtained during official competitions (11) which were in the calendar of Turkish Athletic Federation. The data collection process started after the approval of Sakarya University Ethics Committee and with the permission of the Turkish Athletic Federation.

Research Design: The photocells used to determine running times of athletes were placed at $1 \mathrm{~m}, 6 \mathrm{~m}$ and $11 \mathrm{~m}$ behind the takeoff board (Smart Speed, Fusion Sport, Australia). Velocities for the $11 \mathrm{~m}-6 \mathrm{~m}$ section (V1), the $6 \mathrm{~m}-1 \mathrm{~m}$ section (V2), the total $10 \mathrm{~m}$ (V10) and the difference between V2 and V1 (Vloss) were calculated for each jump. The official jump distances were recorded.

Statistical Analysis: General characteristics of the participants were presented as means and standard deviations ( $( \pm \mathrm{SD})$. Pearson correlation coefficients (r) were used to express the relationships between parameters. Interpretation of correlation coefficients was as follows: $\mathrm{r} \leq 0.49$ weak relationship; $0.50 \leq \mathrm{r} \leq 0.74$ moderate relationship; and $r \geq 0.75$ strong relationship [15]. Linear regression analysis was used to find coefficients of determination $\left(\mathrm{r}^{2}\right)$ for the relationships. For the statistical procedure, IBM-SPSS 20.0 software was applied and statistical significance was set at $\mathrm{p}<0.05$.

\section{Results}

The demographic information about the sample is given in Table 1. The mean official distance of the jumps was found as $6.30 \mathrm{~m}$, and the mean last $10 \mathrm{~m}$ run-up velocity (V10) was found as $8.89 \mathrm{~m} / \mathrm{s}$.

Correlation statistics were calculated between jumping distance and running velocity variables. It was found that the run-up velocity variables V1, V2 and V10 had positive and strong relationships with jumping distance. The correlation between velocity losses and jumping distance was found to a negative and weak relationship ( $r=-0.27$, $\mathrm{p}>0.05)$.

In the regression analysis carried out after the strong relationship ( $\mathrm{r}=0.81)$ found between the distant 5-meter

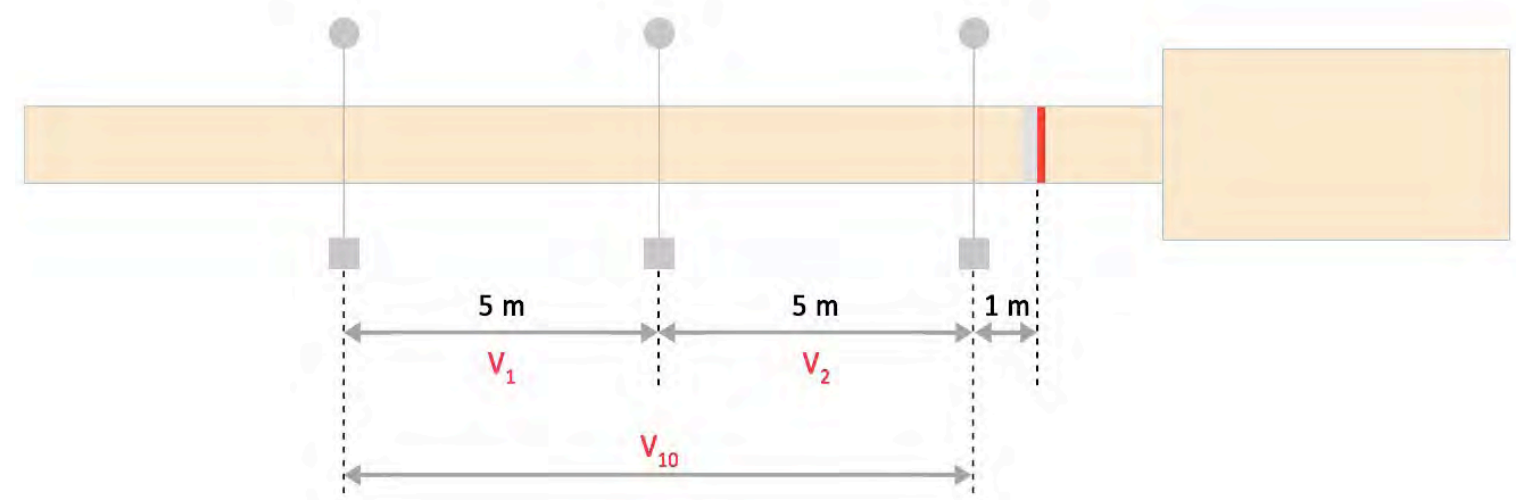

Figure 1. Placement of photocells on the long jump runway

Table 1. Mean and standard deviation values of the age, jumping distance and velocity variables for the sample

\begin{tabular}{|c|c|c|c|c|}
\hline Variables & $\mathbf{n}$ & Mean (SD) & Min & Max \\
\hline Age (year) & \multirow{6}{*}{328} & $18.7(2.8)$ & 14.4 & 28.5 \\
\hline Jump Distance (m) & & $6.30(0.71)$ & 4.53 & 7.74 \\
\hline $\mathrm{V} 1(\mathrm{~m} / \mathrm{s})$ & & $8.88(0.71)$ & 7.08 & 10.89 \\
\hline V2 (m/s) & & $8.92(0.54)$ & 7.52 & 10.20 \\
\hline $\mathrm{V} 10(\mathrm{~m} / \mathrm{s})$ & & $8.89(0.58)$ & 7.29 & 10.32 \\
\hline Vloss (\%) & & $0.71(5.61)$ & -11.66 & 17.82 \\
\hline
\end{tabular}


section (V1) of the last 10 meters of the run-up and the jumping distance, it was found that $\mathrm{V} 1$ was a predictor of jumping distance by $66 \%$ (Figure 2). In the regression analysis carried out after the strong relationship ( $\mathrm{r}=0.82)$ found between the near 5-meter section (V2) of the last 10 meters of the run-up and the jumping distance, it was found that V2 was a predictor of jumping distance by $68 \%$ (Figure 3).

In the regression analysis carried out after the strong relationship $(\mathrm{r}=0.87)$ found between the last 10 -meter section (V10) of the run-up and the jumping distance, it was found that V10 was a predictor of jumping distance by $76 \%$ (Figure 4 ).

As a result of the correlation statistics obtained in this study, a linear regression model was formed between V10 and jumping distance, which was observed to have the highest correlation.

Linear regression model of run-up velocity and the jump distance

With the last 10 meters of approach velocity (V10) as the independent variable, and distance of long jump performance (official jumping distance) as the dependent

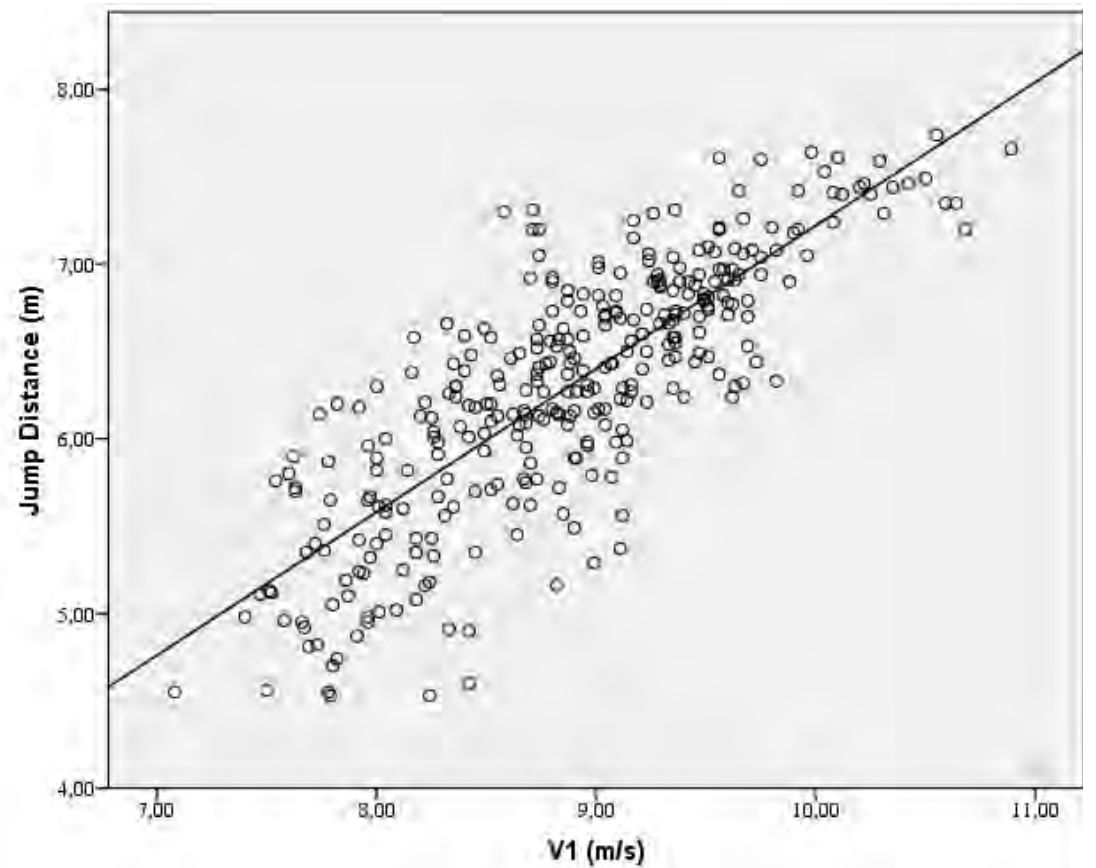

Figure 2. The relationship between the approach run-up velocity which is $\mathrm{V} 1(11-6 \mathrm{~m})$ and official jump distance $\left(r=0.81, p<0.05 ; r^{2}=0.66\right)$

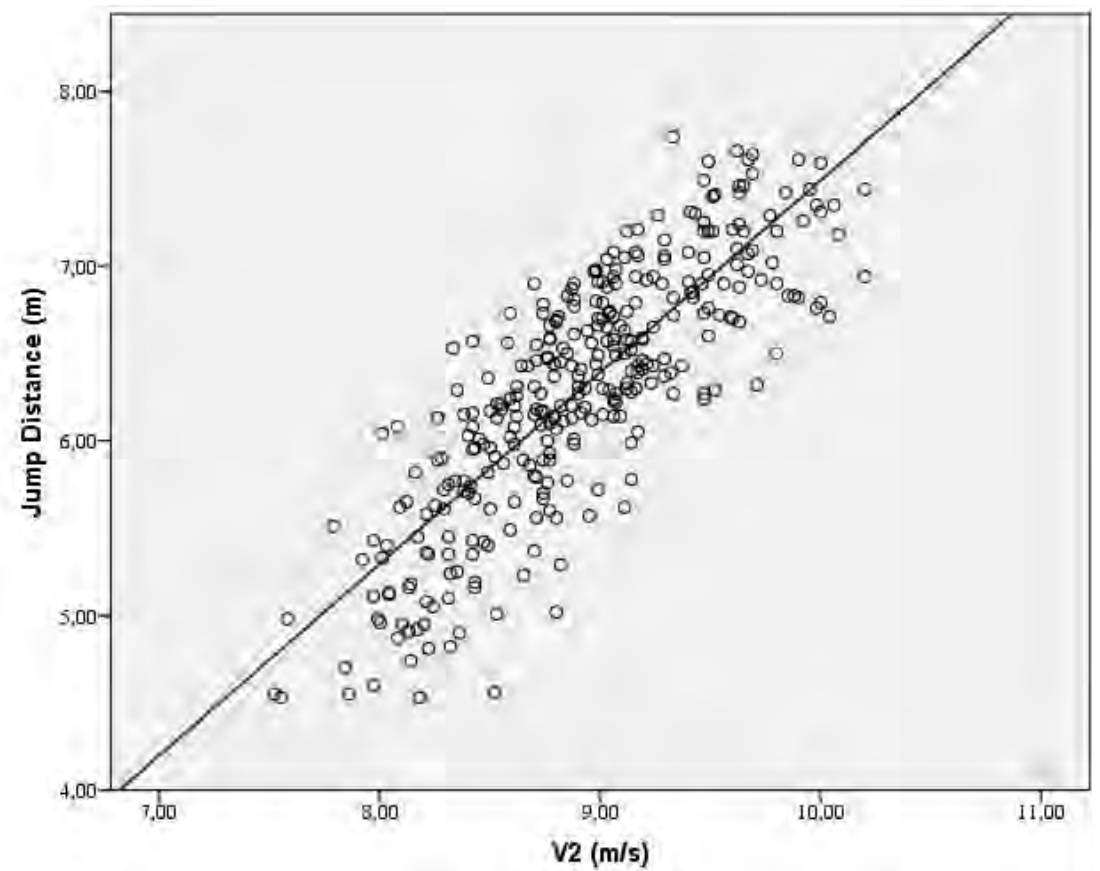

Figure 3. The relationship between the approach run-up velocity which is V2 (6-1 m) and official jump distance ( $r=0.82$, $p<0.05 ; r^{2}=0.68$ ) 
variable, a regression model was established.

As a result of the simple linear regression analysis, it was observed that there was a significant relationship between the velocity in the last ten meters of run-up and jumping distance $(\mathrm{r}=0.87)$. It was found that the velocity in the last ten meters of run-up was a strong predictor of jumping distance $(F(1-326)=1026.38, p<0.05)$. In this case, the velocity value in the last ten meters of runup explained the jumping distance by $76 \%$. The main estimated variable coefficient of the regression equation $(\mathrm{B}=1.067)$ also showed that run-up velocity was a significant determinant $(\mathrm{p}<0.05)$ (Table 2$)$.

According to the regression analysis, the equation for estimating the jumping distance in long jump is as the following:

$$
\mathrm{Y}=(1.067 \mathrm{X})-3.184
$$

Predictive Jump Distance $=Y$, Velocity of last 10 meters $($ V10) $=X$

Based on the estimating equation, it may be stated that $0.1 \mathrm{~m} / \mathrm{s}$ of increase in run-up velocity for male long jumpers will increase their jumping distance by $10.7 \mathrm{~cm}$.

\section{Discussion}

According to the results of our study, statistically significant, positive and strong $(\mathrm{V} 1=0.81, \mathrm{~V} 2=0.82$, $\mathrm{V} 10=0.87)$ relationships were observed between the runup velocity variables and jump distance. Bridgett and Linthorne [10] studied with a group which had a mean jumping distance of $7.89 \mathrm{~m}$ and a mean run-up velocity of $10.4 \mathrm{~m} / \mathrm{s}(\mathrm{n}=22)$.

They observed a strong correlation (0.96) between horizontal velocity and jumping distance. Mishra and Rathore [12] also found a strong relationship between the run-up velocity variables and jump distance $(r=0.81$, $\mathrm{p}<0.05$ ). Their sample group had a mean jumping distance of $4.71 \mathrm{~m}$ and a mean run-up velocity of $7.37 \mathrm{~m} / \mathrm{s}(\mathrm{n}=46)$. Moura et al. [11], in their study with 23 long jumpers, found a mean jumping distance of $7.32 \mathrm{~m}$ and a mean run-up velocity of $9.90 \mathrm{~m} / \mathrm{s}$. They reported the correlation between run-up velocity and jumping distance as 0.72 .

According to the results of the regression analysis in our study, it was shown that $76 \%$ of jumping distance may be explained by the variable of velocity in the last 10 meters of run-up (V10) $\left(r^{2}=0.76\right)$. Nelson and Zebas [16], as a result of the regression analysis they conducted

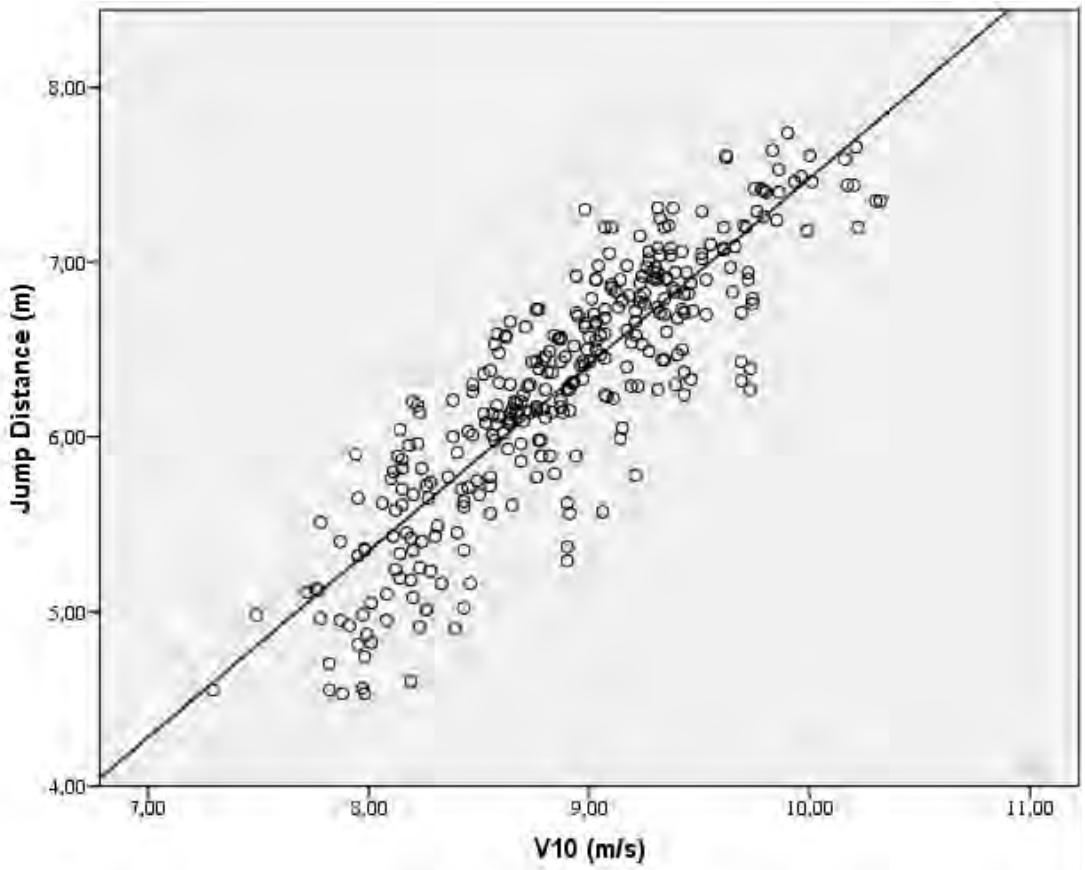

Figure 4. The relationship between the approach run-up velocity which is V10 (11-1 $\mathrm{m})$ and official jump distance $\left(r=0.87, p<0.05 ; r^{2}=0.76\right)$

Table 2. Significant test results of regression coefficients

\begin{tabular}{lllllll}
\hline Model & & \multicolumn{2}{l}{ Unstandardized Coefficients } & Standardized Coefficients & t \\
& & B & Std. Error & Beta & Sig. \\
\hline \multirow{2}{*}{1} & (Constant) & -3.184 & .297 & & -10.729 & .000 \\
& V10 & 1.067 & .033 & .871 & 32.037 & .000 \\
\hline
\end{tabular}

a. Dependent Variable: Distance 
between the horizontal velocity variable and jumping distance, reported that \%46 of jumping distance may be explained by horizontal velocity.

The estimation model presented in this study based on the horizontal velocity variable in the last 10 meters of run-up (11-1 m):

$$
\mathrm{Y}=(1.063 \mathrm{X})-3.152
$$

Predictive Jump Distance $=Y$, Velocity of last 10 meters $(V 10)=X$

According to the estimating equation of this study, it may be stated that an increase of $0.1 \mathrm{~m} / \mathrm{s}$ in the runup velocities of male long jumpers will increase their jumping distance by $10.7 \mathrm{~cm}$. In another study it was stated that the same increase in the run-up velocity will increase jumping distance by $6 \mathrm{~cm}$ [10]. Hay [17], in their review named the biomechanics of the long jump, wrote about three different studies on this topic. Based on an increase of $0.1 \mathrm{~m} / \mathrm{s}$ in run-up velocities, the first study reported an increase of 8-10 $\mathrm{cm}$, the second study reported an increase of $12 \mathrm{~cm}$ and the third study reported an increase of $8 \mathrm{~cm}$ in the jumping distance. Again, Hay [7], in their study investigating the relationship between jumping distance and run-up velocity $(n=306)$, reported an increase of $12.8 \mathrm{~cm}$ in jumping distance related to an increase of $0.1 \mathrm{~m} / \mathrm{s}$ in run-up velocity. Bridgett et al. [9] reported that each $0.1 \mathrm{~m} / \mathrm{s}$ increase in the run-up velocity of an athlete will increase the athlete's jumping distance by $8 \mathrm{~cm}$. The findings of this study are in parallel with the previous ones.

In a study on model values about elite long jumpers, Linthorne [2] emphasized that male long jumpers need to have a horizontal velocity value of $10.6 \mathrm{~m} / \mathrm{s}$ to reach 8.00 meters of jumping distance. According to the estimating equation of this study, for an athlete to be able to jump 8.00 meters forward, he should have a velocity of $10.5 \mathrm{~m} / \mathrm{s}$. The last-ten-meter run-up velocity of the athlete who came first $(8.54 \mathrm{~m})$ in the 2009 Berlin IAAF World Championship was recorded as $10.99 \mathrm{~m} / \mathrm{s}$ in the biomechanical analysis report [4]. In this estimation model, this athlete would complete a jump of 8.54. Moura et al. [11] reported that the long jumpers in their sample jumped a minimum of $6.52 \mathrm{~m}(9.09 \mathrm{~m} / \mathrm{s})$, a maximum of $7.99 \mathrm{~m}(10.42 \mathrm{~m} / \mathrm{s})$ and a mean of $7.32 \mathrm{~m}(9.90 \mathrm{~m} / \mathrm{s})$. According to the run-up velocity values mentioned about, these values estimated for the present study were found as minimum $6.51 \mathrm{~m}(9.09 \mathrm{~m} / \mathrm{s})$, maximum $7.93 \mathrm{~m}(10.42 \mathrm{~m} / \mathrm{s})$ and mean $7.38 \mathrm{~m}(9.90 \mathrm{~m} / \mathrm{s})$. In another study, Bridgett and Linthorne [10] found a mean jumping distance of $7.89 \mathrm{~m}$ and a mean run-up velocity of $10.4 \mathrm{~m} / \mathrm{s}$. If we apply the mean run-up velocity value of their study in the estimation model here, this athlete would be able to jump 7.91 meter with a run-up velocity of $10.4 \mathrm{~m} / \mathrm{s}$. As it may be seen, the estimation equation presented in this study is able to use run-up velocity values from different studies and produce jumping distance estimations that are very close to their findings.

\section{Conclusions}

Consequently, the strong relationship found between run-up velocity in the last 10 meters and jumping distance in long jumping, shows that run-up velocity was a significant factor in this sample. It was observed that especially the velocity in the last 10 meters of run-up was one of the most significant predictors of performance, and the estimation model established using the value of runup velocity, which had the strongest relationship, was able to make high-accuracy estimations for both low and high values.

\section{Highlights}

The "technical efficacy score" calculation given below may be proposed for trainers to gain information about the current status of their athletes' technical capacities and make comparisons. This calculation is made by dividing the jumping distance achieved by the athlete during training or competition, by the jumping distance estimated based on the run-up velocity of the athlete using the model established in this study (Technical efficacy score $=$ Measured distance $/$ Estimated distance). If the score obtained as a result of this calculation is lower than 1 , this means the technical efficacy of the athlete is low, while on the other hand, if the score is higher than 1, this means the technical efficacy of the athlete is high.

\section{Acknowledgments}

This study was supported by the Presidency of Turkish Athletic Federation. Special thanks to all athletes who participated in the study.

\section{Conflict of interest.}

The authors state that there is no conflict of interest. 


\section{References}

1. Hay JG, Miller JA, Canterna RW. The techniques of elite male long jumpers. J Biomech. 1986;19:855-66.

2. Linthorne NP. Biomechanics of the Long Jump. In: Hong Y, Bartlett R, editors. Handb Biomech Hum Mov Sci. Routledge; 2008. P. 340-54.

3. Derse E, Hansen J, Tim O, Stolley S. Track and Field Coaching Manual. LA84 Foundation; 2012.

4. Hommel H. Long Jump (Final Report) - Scientific Research Project Biomechanical Analyses at the IAAF World $\mathrm{CH}$ in Athletics - Berlin 2009 [Internet]. 2009 [updated 2009 Feb 10; cited 2017 Apr 10]. Available from: https://www.iaaf.org/ development/research

5. Fukasiro S, Wakavama A. The men's Long Jump. New Stud Athl. 1992;7:53-6.

6. Açıkada C, Arıtan S, Yazıcıoğlu M V. 1992 Balkan Gençler Şampiyonası Uzun Atlama Yaklaşma Koşusunun Analizi. [Analysis of the 1992 Balkan Junior Championship Long Jump Approach Run.]. Atlet Bilim ve Teknol Derg. 1993;9:34-40.

7. Hay JG. Citius, altius, longius (faster, higher, longer): the biomechanics of jumping for distance. $J$ Biomech. 1993;26:7-21.

8. Lees A, Graham-Smith P, Fowler N. A Biomechanical Analysis of the Last Stride, Touchdown, and Takeoff Characteristics of the Men's Long Jump. J Appl Biomech. 1994;10:61-78.
9. Bridgett LA, Galloway M, Linthorne NP. The effect of runup speed on long jump performance. In: Gianikellis KE (ed.). Sci Proc XXth Int Symp Biomech Sport. Cáceras, Spain: Universidad de Extremadura; 2002. P. 80-3.

10.Bridgett LA, Linthorne NP. Changes in long jump takeoff technique with increasing run-up speed. J Sports Sci. 2006;24:889-97.

11. Moura NA, de Paula Moura TF, Borin JP. Approach speed and performance in the horizontal jumps: What do Brazilian athletes do? New Stud Athl. IAAF publications; 2005;20:4345.

12.Mishra MK, Rathore VS. Speed and agility as predictors of long jump performance of male athletes. Turkish J Sport Exerc. 2016;18:27-33.

13.Schulek A. Long jump with supramaximal and normal speed. IAAF new Stud Athl NSA. 2002;17:37-43.

14. Hay JG, Miller JA. Techniques Used in the Transition From Approach to Takeoff in the Long Jump. Int J Sport Biomech. $1985 ; 1: 174$

15.Portney LG, Watkins MP. Foundations of clinical research. Applications to practice. 3rd ed. Philadelphia: F. A. Davis Company; 2015.

16.Nelson JD, Zebas CJ. Predictors of Horizontal Velocity in the Takeoff of the Long Jump and Triple Jump Hop. 6 Int Symp Biomech Sport. 1988;181-5.

17.Hay JG. The Biomechanics of the Long Jump. Exerc Sport Sci Rev. 1986;14:401-46.

\section{Information about the authors:}

Bayraktar I.; http://orcid.org/0000-0003-1001-5348; The Ministry of Youth and Sport, General Directorate of Sport; Balgat Mh. Osmanlı Cd. 25/2 Çankaya Ankara. Turkey.

Çilli M. (Corresponding Author); http://orcid.org/0000-0002-9027-363X; mcilli@sakarya.edu.tr; Faculty of Sport Sciences, Department of Coaching Education, Sakarya University; Faculty of Sport Sciences, Department of Coaching Education, Sakarya University, Serdivan, Sakarya, Turkey.

Cite this article as: Bayraktar I, Çilli M. Estimation of jumping distance using run-up velocity for male long jumpers. Pedagogics, psychology, medical-biological problems of physical training and sports, 2018;22(3):124-129. doi:10.15561/18189172.2018.0302

The electronic version of this article is the complete one and can be found online at: http://www.sportpedagogy.org.ua/index.php/PPS/issue/archive

This is an Open Access article distributed under the terms of the Creative Commons Attribution License, which permits unrestricted use, distribution, and reproduction in any medium, provided the original work is properly cited (http://creativecommons.org/licenses/by/4.0/deed.en).

Received: 09.03.2018

Accepted: 06.04.2018; Published: 30.06.2018 